\title{
LAS CREENCIAS EN LA VIDA HUMANA UNA APROXIMACIÓN A LA DISTINCIÓN ORTEGUIANA \\ ENTRE IDEAS Y CREENCIAS
}

José Lasaga Medina

\begin{abstract}
" ¿No comienza el cultivo del espiritu científico cuando uno no se permite ya más convicciones?... Asi es probablemente. Sólo resta por preguntar, para que este cultioo pueda comenzar, si no ha de haber ya una convicción, y por cierto, tan imperiosa $e$ incondicional que se sacrifiquen por ella todas las restantes conoicciones. Se ve que también la ciencia se apoya sobre una fe, no existe ciencia alguna 'libre de supuestos'".
\end{abstract}

F. Nietzsche

\section{Introducción}

Si hubiera llegado a existir un libro con el título de Aurora de la razón histórica, su primer capítulo se habría titulado "Ideas y creencias". Ortega no llegó a escribir -o al menos a publicar o conservar- tal libro pero una parte sustancial de ese capítulo inicial apareció en 1936 vertido al alemán en la Europäische Revue. La publicación española de "Ideas y creencias" tuvo que esperar hasta 1940 en una edición argentina. Sin embargo, algunas de las tesis de este importante artículo habían sido adelantadas en el trabajo titulado "Historia como sistema" redactado como homenaje a Cassirer y publicado en el volumen colectivo Philosophy and History [edición de Klibansky, Oxford University Press, 1935]. El texto estaba disponible en inglés en esta fecha pero su edición española se demora hasta 1941. Previos a estos dos breves trabajos que encierran la expresión plena de la teoría de la creencia -prueba de ello es que Ortega siempre que vuelva sobre las nociones de "creencia", "idea" o sobre su relación, acostumbre a citar los mencionados artículos- hay que tener en cuenta, si se quiere

Éndoxa: Series Filosóficas, $n^{\circ} 4$, 1994, UNED, Madrid:

José Lasaga Medina: Las creencias en la vida humana. (Una aproximación a la distinción orteguiana entre ideas y creencias).

pp. 205-231. 
establecer mínimamente su génesis ${ }^{1}$, los cursos dictados por Ortega en la universidad madrileña: En torno a Galileo (ETG) (1933), ¿Qué es conocimiento? (QC) (1930-1933) y Unas lecciones de metafísica (LM) (1932-33).

1 La génesis de la teoría de las creencias se remonta a los orígenes de la obra madura de Ortega. En su ensayito de 1915 "La guerra, los pueblos y los dioses" y antes en su texto sobre Baroja - Pío Baroja: anatomía de un alma dispersa"- maneja una noción de mito cuyo significado se aproxima mucho a la de creencia. Mito es "lo que pensamos cuando no pensamos como especialistas" $(I, 416)$... "los pensamientos espontáneos que van por las calles"; incluso llega a emplear ya la noción de creencia: "las creencias básicas de nuestro edificio espiritual". "La mitología ambiente es al fin y al cabo un mundo pleno y unitario donde las cosas pueden sustentarse cada una en el hombro de su vecina" (IX,496). Aunque Ortega cita como fuente a Schelling [en "La guerra, los pueblos y los dioses": "...un pueblo es, en última instancia, su mitología, su idea de divinidad" (I,414)l, es posible que esté influyendo aquí la idea de mito de Sorel quien en sus Reflexiones sobre la violencia observa: "los mitos no son sólo descripciones de cosas, sino expresión de voluntades", según cita del profesor Cacho Viu en "La imagen de las dos Españas" [Reoista de Occidente, Madrid, $\mathrm{n}^{\circ}$ 60, mayo 1986, p. 65.]. Desde luego, Ortega subrayará en la creencia la dimensión ejecutiva, activa de lo que sin ser propiamente racionalidad, es su condición de posibilidad.

Marías ha insistido en que "la distinción entre ideas y creencias está ya claramente formulada en Vieja y nueva política" (Acerca de Ortega, Madrid, Revista de Occidente, 1971, p. 151), y cita, entre otros, el siguiente texto: "Allá el fondo oscuro e íntimo de nuestra personalidad no se siente ligado a esas opiniones que dicen nuestros labios o que hace como que piensa nuestra mente; no son opiniones sentidas; no son, por tanto, nuestras opiniones" (I, 269).

Esta "realidad de subsuelo" que condicionaría el pensar efectivo de una generación o de una parte de la sociedad es retomada en El tema de nuestro tiempo bajo la tesis de que el fenómeno primario en historia es la sensibilidad vital, entendiendo por tal una cierta amalgama de "ideología, gusto y moralidad" (III,146). Adviértase que esa sensibilidad vital, siendo lo que "hay que definir para comprender una época", funciona como claro precedente del sistema de creencias.

Un texto de 1925 describe claramente el estatuto de las creencias, oponiéndolas a aquello que se razona:"Nada profundo y evidente nace ni vive de razones. Se razona lo dudoso, lo probable, lo que no creemos del todo.

"Cuanto más profundo y elemental sea un ingrediente de nuestra convicción, menos nos preocuparemos de él, $y$, en rigor, ni siquiera lo percibimos. Vamos viviendo sobre él; es la base de todos nuestros actos e ideas. Por lo mismo, queda fuera de nosotros, como está fuera de nosotros el palmo de tierra que pisamos, el único que no podemos ver y que el pintor no puede transportar al lienzo". ("El arte en presente y en pretérito", In, 425).

Y en "Sobre el amor" (1927): "Las ideas mismas de que la razón se compone nos llegan hechas y listas de un fondo oscuro, enorme que está situado debajo de nuestra conciencia" $(\mathrm{V}, 602)$. 
En el primero de los cursos mencionados (ETG) se expone la tesis de que la circunstancia se ordena en mundo gracias a las convicciones que el viviente tiene sobre lo que le rodea; estas convicciones no son elaboradas por él, sino que se las encuentra hechas por la sociedad en la que vive; esa sociedad "tiene ya una interpretación de la vida, un repertorio de ideas sobre el universo, de convicciones vigentes" $(\mathrm{V}, 25)$. La noción de "con-vicción", que adelanta la de "creencia" -aunque en mi opinión, no es idéntica a las creencias en sentido estricto porque las convicciones de las que aquí se habla pueden albergar contenido ideativo ${ }^{2}$-, es caracterizada por Ortega como aquello que tiene realidad ejecutiva para el viviente, esto es, aquella instancia desde la cual se determina a actuar o, cabría matizar, desde la que es determinado a actuar.

En QC y LM, al hilo del análisis de la noción de ejecutividad, decisiva para comprender la diferencia que establece la reflexión orteguiana entre vida humana y conciencia, distingue entre las dos formas en que puede "existir algo para mí": como "contar con" y como "reparar en":

"'Reparar', equivale a lo que tradicionalmente se llamaba 'tener conciencia de algo', y el simple 'contar con', expresa esa presencia efectiva, ese existir para mí que tienen siempre todos los ingredientes de mi situación" (XII,41).

La citada distinción es el primer paso en firme para circunscribir el ámbito de la conciencia y limitar su influencia dentro del quehacer vital. El 'contar con' es una realidad vital que pertenece al plano de lo ejecutivo y no al de lo pensado. Ahora bien, aquello

\footnotetext{
2 A título de ejemplo: "Esta tierra que àñra mis pies pisan es una cosa que está ahí, pero la tierra de luego, la del inmediato futuro no está ahí, no es una cosa, sino que tengo yo ahora que inventarla, que imaginarla, que construírmela en un esquema intelectual, en suma, en una creencia sobre ella" (ETG, V, 85. Los subrayados son míos). Leída con atención, se advierte que tan solo hay un uso impropio del término creencia, pues lo que imaginamos son ideas, ocurrencias. Sin embargo, Ortega ya ha establecido sólidamente la oposición esencial entre creencias e ideas, si bien no ha terminado de fijar la terminología. El pasado es creencial. Pero el estar la vida abierta al futuro hace que el sistema de creencias resulte insuficiente para vivir. De ahí que sea necesario pensar, imaginar, elaborar soluciones personales, esto es, ideas.
} 
con lo que cuento es para mí una convicción, una especie de verdad, solo que no una verdad que se haga presente a la conciencia, sino cuya presencia es ejecutiva, esto es pre-intelectual ${ }^{3}$.

La distinción entre los modos de presencia ejecutivo e intelectual de las cosas en el ámbito de actualidad que es toda vida humana coincide prácticamente con la distinción entre creencias e ideas ${ }^{4}$.

\section{Creencias e ideas en una vida humana.}

Una comprensión cabal de la distinción entre creencias e ideas tiene que arrancar de un somero análisis de esa realidad "radical" que es para Ortega la vida humana de cada cual, en el sentido de

\footnotetext{
3 "Esta realidad ta existencia de alguien que cuenta absolutamente con algo- es previa a toda otra. Si digo 'existe pensamiento', es que yo he caido en la cuenta de ello, que me he convencido de ello; y todo esto se ha verificado dentro de una realidad previa a la que nombra aquella proposición, y de la que ésta es sólo resultado y un momento. Más aún: para que una proposición sea verdadera o enunciado teórico exista, es menester que nazca y se nutra de una realidad preteorética que la produce y la sostiene en el ser; es menester que alguien esté actualiter creyendo en ella" (¿Qué es conocimiento?, Madrid, Alianza ed., 1984, pp. 3940).
}

4 En "La noción de creencia en Ortega" -José Ortega y Gasset, México, FCE, 1984, pp.41-76- L. Villoro dice: "Vemos cómo Ortega dobla, sin decirlo expresamente, la distinción ideas-creencias con otra: intelecto-vida" (p. 48). Creo haber demostrado que no es así. Es más, la distinción entre creencias e ideas solo tiene sentido, en la medida en que se entienda siempre referida a la de vida humana-intelecto. En los cursos QC y LM es donde Ortega plantea sistemática y explícitamente la necesidad de conducir el análisis filosófico más allá de lo que es presente a la conciencia, lo que creo que queda ilustrado en el texto de la nota 3. Como Villoro no cita ninguno de estos trabajos es posible que, si los ignora o no los tiene en cuenta, piense que la distinción entre ideas y creencias es la causa -y no el efecto- de la distinción más radical y de principio entre vida e intelecto, cuando es su consecuencia y concreción. Que no ha entendido, en mi opinión, demasiado bien el sentido central de la noción de creencia lo prueba el que a) identifique el sistema de creencias con los marcos conceptuales para la interpretación del mundo (p. 49) o con nuestros "compromisos ontológicos o valorativos" (p. 59), lo que supondría la accesibilidad de la razón a estas creencias, cosa que Ortega niega tajantemente; b) vea coincidencias entre las creencias -bien que superficiales- y las ideologías de clase o grupo social. Éstas, para Ortega, son ideas vigentes, que coinciden con las creencias en que tienen esta propiedad social: la vigencia. Pero no son creencias, aunque actúen como "usos sociales", porque las ideologías se defienden, justifican, etc., lo que es típico de las ideas. Acaso convenga añadir que las idelogías dependen de creencias no expresadas o tácitas, de las que reciben, por cierto, su eficacia "pública". Pero en eso no se diferencian de cualquier otro conjunto de ideas, sistemático o no. 
ser, no fundamento de otras realidades, sino condición de aparición de cualquier otra realidad que será siempre y necesariamente "realidad radicada".

Como cuestión previa hay que plantear la equivocidad que tiene el término "realidad" en el lenguaje filosófico orteguiano. Por un lado "realidad" designa "lo que hay"; así, realidad radical es $l o$ que hay absolutamente, lo primero que hay y que por serlo, es condición no de "ser", sino de "aparecer" de todo lo que luego hay. $Y$ lo que hay no son cosas, ni ideas, sujetos u objetos, sino vida humana individual. Por otro, "realidad" designa el modo de haber lo que hay o consistencia de lo que hay.

Lo que hay consiste (o se da) no como substancia, sino como acontecimiento. No cabe, pues, hablar de realidades-en-sí, sino de realidades-para. La realidad se manifiesta como relación; pero no como relación a un sujeto cognoscente como creyó Kant, sino como interacción ejecutiva entre un yo y su circunstancia.

El enunciado "lo que hay radicalmente es vida humana individual" desplaza el problema de la realidad al interior de la relación yo-circunstancia. Nos encontramos entonces con otro sentido del término realidad: realidad radicada: la realidad de lo que aparece en el interior de cada vida humana; y esto que aparece constituyendo las vidas humanas son situaciones, quehaceres, problemas, referidos, en última instancia, a dos cuestiones: ¿qué realidad tengo yo para mí mismo? y ¿qué realidad tiene lo que aparece ante mí, como trascendente y resistente a mí: la circunstancia, el mundo ${ }^{5}$

5 Quedará más claro este somero análisis del término realidad si

a) disponemos estas distinciones en un esquema:

REALIDAD RADICAL: acontecimiento del vivir:

lo que acontece entre un yo y su circunstancia

REALIDAD RADICADA:

Niveles o Modos:

1) realidad desnuda (de toda interpretación)

yo - enigma (del vivir) 
En tanto que realidad radical, la vida humana es quehacer, más exactamente: "lo que hacemos y lo que nos pasa". Toda vida es para sí misma el quehacer del yo que la habita; ese habitar consiste en encontrarse teniendo que hacer algo en una circunstancia a la que se ve consignado y ese "lo que hace" es su vida. Por ser la vida "dada" pero dada "sin hacer" es libertad. Ser libertad, esto es, tener que hacer algo, es decidir qué es menester hacer. De ahí que también sea "saber a qué atenerse". Esto fuerza al yo a interpretar la circunstancia:

"Vivir es ya encontrarse forzado a interpretar nuestra vida. Siempre, irremisiblemente, en cada instante, nos hallamos con determinadas convicciones radicales sobre lo que las cosas son y nosotros entre ellas: esta articulación de convicciones últimas hacen de nuestra circunstancia caótica la unidad de un mundo o universo $(\mathrm{V}, 24)$.

Es evidente que el viviente estaría en un estado de desorientación si no hubiera ya en su entorno un "sistema" de instancias orientadoras. En el texto citado se nos dice claramente que son "determinadas convicciones radicales". El término "convicción" podría traducirse por el de evidencia o certeza. ¿Pero de qué tipo de evidencia se trata? ¿De una evidencia intelectual? $Y$ lo que es más importante, ¿se trata de una evidencia alcanzada por el yo pensante mediante un esfuerzo de reflexión? A ambas preguntas responde Ortega negativamente. Las convicciones que ordenan el mundo con que se encuentra el viviente son, en su mayor y decisiva parte, heredadas de la sociedad. Vivir presupone un componente de facilidad que se nos tiene que dar más o menos elaborado. La circunstancia que es lo extranjero al yo y en sí

2) rea'idad interpretada

a) por creencias

b) por creencias e ideas yo - mundo (interpretado)

b) añadimos a lo ya dicho otra caracterización de "realidad" en los términos siguientes: "la contravoluntad, lo que nosotros no ponemos; antes bien, aquello con que topamos" $(\mathrm{V}, 389)$. 
misma enigmática, lo que se le opone y resiste radicalmente, ha de contener un sistema de referencias para que el yo pueda organizar mínimamente su quehacer. La circunstancia es simultáneamente mundo físico y mundo social, materialidad o Naturaleza y mundo humano decantado en interpretaciones, usos, estimaciones, experiencias, utensilios, prácticas, etc.; este segundo recubre -y, al recubrir, oculta, no se olvide-con sus "facilidades" el primero y lo hace vivible, esto es, humano.

El viviente vive apoyado sobre sus pies, no sobre su cabeza; y sus pies descansan sobre la tierra, esto es, sobre una cosa firme capaz de sostener. Eso firme capaz de sostener es lo que llama Ortega un sistema de creencias.

Podemos establecer estas dos primeras tesis: a) las cosas se hacen presentes al viviente como creencias; b) las creencias no pueden nunca ser, como tales, contenidos de conciencia, esto es, ideas.

Tanto en ETG como en LM había quedado establecido que la forma primaria de presencia de las cosas ante el yo no era de objeto ante sujeto sino de convicción ejecutiva, actuante, pragmática para un yo igualmente ejecutivo ${ }^{6}$. Solo después de que algo

6 Este plano ejecutivo parece corresponder a lo que llama Husserl "mundo natural" o "mundo de la vida", para usar la expresión que preferirá en su última obra La crisis de las ciencias europeas y la fenomenología tras-cendental [Barcelona, Crítica, 1991]: "El mundo de la vida es el mundo espacio -temporal de las cosas tal y como las experimentamos en nuestra vida pre- y extracientifica y tal y como las sabemos como experimentables, más allá de que de hecho sean experimentadas. Tenemos un horizonte mundano como horizonte de posible experiencia de cosas" (p. 145-146).

Aunque hay una gran proximidad entre este "mundo de la vida" y el mundo o circunstancia dado al viviente, según Ortega, hay dos diferencias que afectan al sentido central de una y otra filosofa: a) Husserl no describe el mundo de la vida en términos de una realidad creencial, de fuerte componente social, ajena a la conciencia; b) Husserl mantiene intacto su proyecto originario de encargar a la conciencia la epojé del mundo de la vida para crear una ciencia radical y fundamental, lo que implica la posibilidad de constituir racionalmente la totalidad del mundo de la vida.

Se pide a la filosofía que realice una epojé radical para salvar el mundo de la vida de cualquier impostura o recubrimiento conceptual por parte de las ciencias objetivas, de modo que el objeto de la filosofía sería el de constituirse como saber 
esté ejecutándose puede sobrevenir su contracción a objeto, esto es, a idea o representación de conciencia. Pero primero ha tenido que pasar algo entre el yo y las cosas; lo mínimo es que se hayan hecho presentes en forma ejecutiva: que pueda el yo contar con ellas. $Y$ se hacen presentes gracias a las creencias.

En definitiva y puesto que vivir es "tener que habérselas" con algo -la circunstancia y el propio sí mismo- frente a lo que el viviente se encuentra, ese algo se le aparece en forma de interpretaciones heredadas:

"A esas 'ideas' básicas llamo 'creencias'. Esas ideas que son, en verdad, 'creencias' constituyen el continente de nuestra vida y por eso no tienen el carácter de contenidos particulares dentro de ésta" $(\mathrm{V}, 384)$.

La distinción entre creencias e ideas parece clara. Idea es lo que desde Descartes se considera tal, un contenido mental, cognitivo,

racional del mundo de la vida. No es aquí ocasión de discutir la viabilidad de tal proyecto, pero sí la de señalar que al caracterizar Ortega la circunstancia mundana como "horizonte de creencias" y no de meras "experiencias", estipula ya la imposibilidad de que la razón pueda acceder metódicamente al conocimiento de aquellas. Husserl sigue creyendo que la razón puede fundar sus saberes. Ortega concluye que todo conocimiento descansa sobre un acto creencial inabordable directamente por la razón.

Habermas ha criticado la pretensión fenomenológica de acceder metó-dicamente al mundo de la vida: "Lo que Alfred Schütz (...) no vio, sin embargo, fue precisamente un problema, a saber: que no depende de la elección de una determinada actitud teórica el que el mundo de la vida escape en su opaca autoevidencia a la mirada indagadora del fenomenólogo o se abra a ella" (Teoría de la acción comunicatioa II, Madrid, Taurus, 1987, p. 569). La razón de esta imposibilidad la expone en la página anterior cuando reconoce que ninguna teoría de la sociedad puede aspirar a hacer explícitas las estructuras del mundo de la vida, por tratarse de "un saber de fondo sobre el que nadie puede disponer a voluntad. Al teórico, lo mismo que al lego, el mundo de la vida le está dado' por de pronto como su propio mundo de vida..." (op. cit., p. 568). A esta crítica escapa Ortega, que describe las creencias -el elemento determinante de su versión del mundo de la vida o circunstancia- como incons-cientes de suyo, de tal modo que sólo cuando han dejado de operar como tales creencias, pueden ser accesibles al análisis intelectual. "Solo un terremoto -añade Habermas- nos hace cobrar conciencia de que habíamos considerado incon-movible el suelo en que estamos y nos movemos a diario" (Ibid.). Ortega des-cribe su "sistema de creencias" como el suelo en que estamos y nos movemos a diario: "El hombre en el fondo, es crédulo o, lo que es igual, el estrato más profundo de nuestra vida, el que sostiene y porta todos los demás, está formado por creencias. Éstas son, pues, la tierra sobre la que nos afanamos" $(V, 392)$. 
fruto de las capacidades y operaciones intelectivas de la conciencia. Las creencias son un tipo de interpretaciones que no pertenecen a la conciencia, sino que respecto de ella, son siempre "contenidos latentes" dicho: las ideas las tenemos nosotros, son nuestras ocurrencias -en ultima instancia: nuestras fantasias y metáforas ${ }^{8}$; en cambio, las creencias "nos tienen a nosotros" -eso es lo que significa que son el continente de nuestra vida: lo que contiene, envuelve, condiciona -aunque no absolutamente- los haceres en que consiste una vida. Tenemos y producimos nuestras ideas, pero somos nuestras creencias. Aquellas son intercambiables, revocables, materia de discusión, se las puede sostener o abandonar; las creencias, en la medida en que ni se improvisan ni se eligen, sino que se imponen a la vida como desde fuera del vivir, "constituyen la realidad irrevocable y grave de la seriedad de nuestra vida" (XII,158).

Creencias e ideas se distinguen, pues, por las funciones que desempeñan en la vida humana. El sistema de creencias -suelo o continente de la vida, aquello en que la vida está- da a ésta su estructura concreta (VI,14), formando "el estrato básico y más profundo de la arquitectura de nuestra vida" $(\mathrm{VI}, 18)^{9}$. Las ideas cuya función es muy importante, en la medida en que son éstas las que cumplirán la faena de orientarnos en todo aquello en que estemos sin creencias, son siempre vicarias y subsidiarias de las

7 Ortega habla, por ejemplo, de "implicaciones latentes" (V, 387), en el sentido de supuesto tácitos de los que no hay representación ideográfica.

8 La razón, en el sentido de "aparato intelectual" es para Ortega imaginación: "La razón no es sino un modo, entre muchos, de funcionar la fantasía" (VIII,161).

9 En "Creer y pensar", primer capítulo de Ideas y creencias repite Ortega esta tesis, casi con las mismas palabras: "...el estrato más profundo de nuestra vida, el que sostiene y porta todos los demás, está formado por creencias" (V, 392). Pero añade una nota a pié: "Dejemos intacta la cuestión de si bajo ese estrato más profundo no hay aún algo más, un fondo metafísico al que ni siquiera llegan nuestras creencias". La alusión, sin más pistas por cierto, a este "fondo metafísico" es dificil de interpretar. Soy de la opinión de que debe entenderse referido al modo de darse el mundo al yo: el modo de vivir que describe Ortega como "vida en soledad", en donde el yo opera una especie de virtual suspensión de creencias. Véase un poco más adelante los tres modos de darse lo real al yo según Rodríguez Huéscar. 
creencias. Pensamos ideas porque en algún respecto estamos sin creencia, es decir, que pensamos cuando no tenemos delante clara realidad $o$, simplemente, no tenemos realidad a que atenernos (en la que sostenernos). Idear es lo que hacemos cuando tenemos un problema. De ahí que toda ocurrencia -sea del tipo que sea-surja como reacción a una situación vital pre-definida o condicionada por un sistema previo de creencias. Un esquema podría ayudar a presentar con más claridad la distinción entre creencias e ideas:

\section{circunstancia desnuda $\rightarrow$ SISTEMA DE CREENCIAS $\rightarrow$ situación vital (parcialmente orientada) $\rightarrow$ problemas $\rightarrow$ reacción ideativa}

El esquema muestra que las creencias y las ideas pertenecen a planos de realidad (perspectivas) diferentes dentro del todo unitario que es una vida humana. Rodríguez Huéscar distingue tres grados o modos en que se da lo real al viviente: a) la realidad nuda o desnuda -de toda interpretación-. En ella no hay cosas, ni perfiles claros, ni puntos de orientación; es la realidad como puro problema; b) la realidad interpretada en forma de creencias. Es a este modo al que conviene el nombre convencional de "mundo". Las cosas existen "para mí", como instancias de mi quehacer o "prágmatas" (facilidades o dificultades); c) la realidad pensada, imaginada, por tanto mundo de "cosas" e "ideas". La "consistencia" de este mundo depende no solo del sistema de creencias, sino de las respuestas personales que cada cual dé a las dificultades que aparecen en las situaciones del propio vivir. En este plano, las cosas tienen o pueden tener un "en-sí" o esencia ${ }^{10}$.

\footnotetext{
10 A. Rodriguez Huéscar, Perspectioa y verdad, Madrid, Revista de Occidente, 1966, p. 130.De esta realidad de cada vida humana individual, dada en tres grados o estratos, según la presentación sistemática que ofrece Huéscar, conviene insistir en la más recóndita e inasible de las tres, esa realidad "nuda o desnuda", "preinterpretada y premundana": "En este grado primigenio la realidad es puro enigma. No hay 'cosas en ella; no hay más que problemas; es la pura problematicidad. Pero, por otra parte, es la realidad más autentica, aquella a que hemos de descender por debajo de todas sus interpretaciones cuando queremos tomar contacto con la
} 


\section{Función de las creencias.}

Hasta aquí hemos distinguido dos especies de interpretaciones que funcionan de muy distinta manera en el unicum que es cada vida humana. Pero aún no ha sido definido formalmente ese ingrediente de la vida que consiste en que ésta existe contenida por aquél, el conjunto de sus creencias. A la pregunta ¿qué son las creencias? hay que responder separando lo que es su consistencia de lo que es su función, que ya conocemos. La creencia consiste en ser una interpretación de convicción o ejecutiva, un principio pragmático de la vida de cada cual que forma parte de un todo orgánico -sistema, estructura, horizonte- caracteristico de una sociedad y de una época. Puesto que no todas las creencias lo son en el mismo modo, hay que decir que algunas provienen de experiencias básicas que la humanidad viene realizando desde sus orígenes. Otras provienen de las ideas, fueron primero ideas, esto es "soluciones" o respuestas individuales que un viviente creó para su vida a partir de un problema, de una necesidad; luego, esa idea fue adoptada por la sociedad, adquiriendo así un carácter de vigencia que es lo que la convierte propiamente en "creencia". Por tanto, las creencias son interpretaciones vigentes asumidas por toda una colectividad (o una porción suficiente de ésta); la creencia es "vigente por sí", frente y contra nuestra aceptación de ella $(\mathrm{V}, 35)$ :

"Sin duda, las creencias fueron primero ideas, pero ideas que lentamente llegaron a ser absorbidas por las multitudes, perdiendo su carácter de ideas para consolidarse en 'realidades incuestionables' " (VI,61)

Tenemos, pues, que lo producido por la sociedad no es el contenido ideativo -el significado- de la creencia, sino su carácter de tal, esto es, su vigencia. La transformación de una idea en creencia pasa porque aquella pierda su matiz de revocabilidad (de duda,

mismidad de una cosa, es decir, cuando buscamos su verdad" (Ibid.). Y añadamos, con respecto a esta mismidad, que tan necesaria le es a la vida, como imposible su posesión efectiva. La mismidad de la cosa no se deja alcanzar, pero las interpretaciones "verdaderas" encierran aspectos de esa mismidad. 
que es siempre el origen de una idea) y adquiera un halo o nimbo de realidad: las creencias que "contienen" mi vida son para mí como la realidad misma, es decir lo que se me aparece espontáneamente como real. Ahora bien, ningún individuo concreto puede imaginar y conferir a sus ideas ese carácter de "ser la realidad misma" por muy grande que sea la evidencia con que alcance a pensar su idea. Eso solo se puede conseguir por "sugestión social" acumulada históricamente. Los usos e intercambios sociales crean en torno a determinadas ideas algo así como un campo de fuerzas (también se podría decir: dotan a la idea de una especie de poder invisible que sin embargo se manifiesta en los quehaceres vitales) que nunca tiene de suyo una mera idea particular e individual. Este campo es una especie de añadido de "realidad", evidencia compartida que no brota de la adhesión de la conciencia sino que, por decirlo de alguna manera, es lo que provoca o pone en marcha esa reacción de la "luz natural" en que Descartes cifraba el origen de la verdad intelectual.

Al cabo de un tiempo -normalmente largo: la sociedad es tardígrada, suele decir Ortega- ciertas ideas adquieren una cualidad, la de tener "vigencia" o ser vigentes, significando eso que la idea se impone por sí misma, sin necesidad de ser defendida o argumentada; se vuelve entonces indiscutible, hasta el punto de parecer, más que evidente, como revelada ", dotada de una autoridad inapelable. El rasgo principal para definir la vigencia es, pues, su capacidad para ejercer sobre el individuo una coacción, de tal modo que, quiera o no, tiene que contar con aquello que está vigente; y a tal punto ocurre así que normalmente actúan sin darnos cuenta siendo su imposición difusa, atmosférica, latente (o inconsciente). Lógicamente, si ejerce coacción es porque funciona

11 No es posible entrar aquí en el examen de las relaciones entre creencia y revelación, entendido este término como sinónimo de verdad filosófica (en contraposición a otros tipos de verdad menos radicales). No se ignore que aquí se dice como revelada. 
como instancia de poder: "En todo momento podemos recurrir a ella como una instancia de poder en que apoyarnos" $\left(\right.$ VII,266) ${ }^{12}$.

Es conveniente señalar que el sistema de creencias no es homogéneo, en el sentido de que no todas las creencias lo son por igual. Aunque Ortega no se detuvo a elaborar una diferenciación de las creencias, en algunos textos habla de ciertas "creencias básicas" que habría que distinguir de otras más superficiales que se confundirían con lo que podríamos llamar "ideas vigentes" (p.e., ciertos componentes de la opinión pública ${ }^{13}$ ) que aun teniendo

12 No solo las ideas pueden adquirir vigencia, sino que igualmente instituciones, hombres, valores, costumbres, pueden obtenerla.

La relación entre las nociones de "vigencia" y "creencia" es compleja y se haya abierta a discusión. Así, Morón Arroyo propone tratar la idea de vigencia como algo de alcance estrictamente sociológico, mientras que "el tema de la creencia tiene implicaciones psicológicas y epistemológicas que le hacen problema distinto. La subrepticia equiparación o correlación de creencias y vigencias no conduce más que a confusiones'. El sistema de Ortega y Gasset, Madríd, ed. Alcalá, 1968, p. 279.

Morón se refiere a la supuesta confusión que induce Marias cuando caracteriza a las creencias como "un tipo particular de vigencias que se refieren a la interpretación de la realidad". La estructura social, Madrid, Revista de Occidente, 1972, p. 125. Es claro que el difuso "positivismo" que inspira el poco afortunado intento moroniano de construir -por cierto, con una cierta indiferencia hacia la letra y el espíritu de la obra orteguiana- "el" sistema de Ortega no ha hecho pie en el problema metafísico. Arroyo olvida que vigencia, si es definida en términos de "contar con" remite a un nivel metafísico, al igual que la noción de creencia, descrita por Ortega como uno de los componentes estructurales de la vida humana, esto es, de la realidad radical. Si, por otro lado, advertimos que la sociología orteguiana no es una "ciencia humana" en el sentido neopositivista o empirista, sino una parte -la que estudia la dimensión social de la vida- de la teoría general de la vida humana, entonces podemos concluir que la separación entre motivos "epistemológicos" y "sociológicos" que propone Arroyo no lleva a ninguna parte; más bien, escamotea, precisamente, el aspecto decisivo de las creencias: su papel de gozne entre la experiencia inmediata de la vida y los mundos interiores que forman las ciencias y demás saberes. En cualquier caso, Ortega dejó escrito lo siguiente: "La creencia actúa como instalada en nuestro contorno social, el forma de 'vigencia colectiva'..." (VI, 61). Y en La idea de principio en Leibniz, última ocasión en que se ocupa a fondo del problema de las creencias, recuerda que toda creencia efectiva no es sólo "personal, sino colectiva; más aún: incuestionada por el contorno social" (VIII,255).

${ }^{13}$ Un ejemplo de idea vigente sería, actualmente, la tesis de la solidaridad. Esta idea-valor se presenta como un contenido de conciencia que se deja examinar, argumentar, defender, etc., pero es incómodo -socialmente hablando- rechazarla o ignorarla. Se trata, por tanto, de una idea que ejerce coacción social. De la creencia, al permanecer latente a la conciencia, no cabe defenderse pero las ideas de opinión por aparecer en la conciencia son de suyo discutibles. Otra cosa es que la idea 
cierta vigencia no son creencias por carecer de la dimensión de "realidad" irrevocable que caracteriza a éstas. Veamos algún ejemplo de lo que llama Ortega "creencias básicas". Es una creencia básica de mi vida que al tomar la decisión ahora de salir a la calle, cuento con que hay calle; otro ejemplo -tomado de Marías ${ }^{14}$ sería que mañana habrá aire para respirar -porque estoy en la creencia de que el aire es una realidad inagotable-; en general, todas mis percepciones se me imponen como convicciones primarias; en este sentido, se puede decir que el percibir es una función condicionada por el sistema de creencias ${ }^{15}$. Otro conjunto de creencias primarias son las que la lengua materna inyecta en el viviente por medio de las palabras: "El idioma mismo en que por fuerza habremos de pensar nuestros propios pensamientos es ya un pensamiento ajeno, una filosofía colectiva, una elemental interpretación de la vida que fuertemente nos aprisiona" $(V, 25)$. En

vigente, por estar cargada de "autoridad", sea difícil de cuestionar, que resulte incómoda su crítica, como es, por ejemplo, incómodo que nos acusen de "insolidarios".

14 En La estructura social distingue Marías formalmente entre creencias "originarias" y creencias "procedentes de ideas". Estas, a diferencia de las primeras, se presentan "como la realidad misma, pero en forma expresa"; por ejemplo, la creencia en el progreso, tal como la profesa la sociedad europea del XIX (p.141). Esta distinción postula, pues, que hay creencias que no proceden de ideas. El origen de éstas podria explicarse recurriendo a lo que llama Ortega "experiencias categoriales", una de las cuales sería la experiencia que cada cual hace de la muerte, se entiende que de la muerte ajena. Esto parece sugerir Marías cuando indica que "esas creencias no empiezan por ser ideas, sino que nacen de una peculiar vivencia de la realidad, respecto de la cual es siempre secundaria su formulación y expresión mental" (ibid.). Este sería el caso en creencias tales como "en la solidez del suelo, en la inagotabilidad del aire, en la medrosidad del contorno desconocido, en lá pertenencia a una familia o a una tribu, en la existencia de poderes desconocidos" (ibid).

15 En su excelente exposición de la noción de creencia J.C. Gómez Muñoz hace referencia a este papel de las creencias al titular su artículo, justamente, "Creer para ver", Anales del Seminario de Metafísica, $\mathrm{n}^{\mathrm{Q}}$ XVIII, U. Complutense, Madrid, 1983. La creencia en lo que me revelan mis sentidos es primaria, pero puede verse corregida por otras creencias que tengan en un momento dado igual vigencia: " $E l$ que cree copernicanamente que el sol no cae en el horizonte, sigue viéndolo caer, y como el ver implica una convicción primaria, sigue creyéndolo. Lo que pasa es que su creencia científica detiene, constantemente los efectos de su creencia primaria o espontánea". (IV,212). 
otro orden de cosas, el principio de contradicción sería, según Ortega, una creencia heredada y no un principio racional. En La idea de principio en Leibniz argumenta que la evidencia con que, según Aristóteles, se presenta a la razón el citado principio no puede venir nunca de la razón misma, que "no tiene nada que ver con las exigencias de una teoría pura. (...) No es una teoría inteligible, es una institución tradicional, un 'modo' de la 'ciudad' o colectividad, en que ha nacido y que desde niño ha visto respetar a todos" (VIII,212).

Precisamente porque las creencias no lo son de igual manera, sino que admiten grados, forman un sistema ${ }^{16}$ en el sentido fuerte del vocablo, esto es, que tienen una estructura -si bien ésta no es lógica, como le ocurre a las ideas, sometidas a los principios de la razón- y existen apoyándose unas en otras; aunque "las creencias que coexisten en una vida humana (...) son a veces incongruentes, contradictorias o inconexas" ello no obsta para que funcionen como "miembros de un organismo, de una estructura" (VI,14).

Por un lado, la vida humana es de suyo una estructura dotada de sentido y las creencias forman en ella algo así como el bastidor -soporte subyacente y resistente- de la circunstancia. Gracias a que las creencias dan forma a la circunstancia se da ésta como "mundo", esto es, un conjunto de objetos estables, de estructuras de sentido que facilitan la aparición de las cosas en el contexto de las situaciones que el viviente habrá de resolver. Las creencias forman así el sistema de atenimientos -de "referencias", si queremos emplear un término menos orteguiano- de un viviente en su sociedad y época.

\footnotetext{
16 En el artículo citado, Gómez Muñoz escribe lo siguiente sobre el aspecto sistemático de las creencias: "Así, en un momento histórico determinado, para un individuo se arma un sistema que sirve de urdimbre al mundo, ya que éste se cimenta y construye desde él, a su costa. Tal sistema tiende a ser completo pero nunca lo consigue (a tal fin las ideas actúan cubriendo ortopédicamente el hueco de las creencias); se trata pues de un sistema abierto y móvil. Además se estructura en estratos jerárquicos; cada uno de ellos cuenta con mayor relevancia vital que el posterior y, a la vez, le sirve de apoyo". (art. cit., p. 86).
} 
Por otro, las creencias son una de las condiciones de sentido de la conducta humana, pues ésta no viene orientada ni condicionada por las ideas que el sujeto tenga, sino por sus creencias:

"Siempre quedará que lo que efectivamente actuaba en nuestro comportamiento, como que era su único supuesto, no era pensado por nosotros como conciencia clara y aparte. Estaba en nosotros, pero no en forma consciente, sino como implicación latente de nuestra conciencia o pensamiento" $(\mathrm{V}, 387)$.

A este respecto, conviene observar que el "sistema" se arma en la perspectiva del quehacer individual, aun cuando las creencias tengan el carácter "objetivo" y mundano que se le viene reconociendo. Las creencias son un sistema tan solo en la perspectiva del yo-vocación que tiene que realizar su vida.

El sistema de creencias de cada vida humana es, pues, la condición -necesaria, si bien no suficente- de la acción y, por ende, del pensamiento humanos. Una vida humana consiste en su argumento -la estructura de las situaciones por las que pasa el viviente-, estructura determinada por dos componentes: el lecho de creencias -y de los otros sistemas de vigencias de la sociedad-en que se encuentra alojada su vida en función del momento histórico; y el proyecto individual de esa vida, lo que el yo tiene que llegar a ser, el personaje ideal (imaginario) que la espontaneidad creadora, inserta en el fondo de la propia intimidad, proyecta sobre el mundo, concretándose en la figura de una vocación determinada. Creencias y vocación son los componentes del argumento de la vida humana.

Las situaciones efectivas en que se despliega y expone el mencionado argumento quedarán siempre contenidas en lo que para éste es real. Ahora bien ya se ha dicho que lo real para la vida de cada cual es el sistema de creencias en que esté viviendo, aquello con lo que cuenta, quiera o no. Las creencias son pues la realidad efectiva, aunque aquí "realidad" no tiene el sentido metafísico tradicional de "realidad subyacente" o realidad en sí misma, sino que se trata de lo que ejerce como horizonte de 
realidad para el viviente, horizonte que contribuye a determinar el sistema "de lo que se considera como posible y lo que se considera como imposible" (IX,516) ${ }^{17}$. Que las creencias forman el estrato de realidad sobre el que "vivimos, nos movemos y somos" como dice Ortega parafraseando a San Pablo, deja intacta la cuestión "de si bajo ese estrato más profundo no hay aún algo más, un fondo metafísico al que ni siquiera llegan nuestras creencias" (V,392). Intentaré, por mi parte, decir algo sobre la cuestión.

Las creencias son un modo de aparecer-nos lo real, una modalidad de lo real-para, uno entre otros. Esto explica que haya una cierta ambigüedad en la exposición orteguiana cuando describe la forma en que se manifiesta lo real al yo en el interior de su perspectiva vital. Veamos las siguientes afirmaciones:

"Realidad plena y auténtica no nos es sino aquello en que creemos" (V,398).

"La realidad auténtica y primaria no tiene por sí figura" $(V, 400)$. Puesto que figura es lo conferido por el sistema de creencias a la circunstancia desnuda, transformándola en mundo, ambas tesis parecen contradictorias. Pero no hay tal porque se trata de dos modos de darse la realidad al viviente: como solución y como enigma. La aporía pertenece a la propia estructura de la vida humana, por lo que el sistema de conceptos que intenta aprehenderla, no puede hurtarse a ella. Para evitar críticas obvias, Ortega gustaba subrayar, citando a Dilthey, que la vida es precisamente multilateral. Es evidente que la vida se manifiesta simultáneamente como seguridad y perdición, solución y enigma, "tierra firme" y "mar de dudas", salvación y naufragio, aunque en el argumento de

17 En Ortega, "posible" y "real" no mantienen las vieja relación más o menos aristotélica, según la cual, lo real-actual se opone a lo no-real-potencial. En su monografía sobre este aspecto de la metafísica orteguiana -"Para una teoría de la posibilidad basada en el pensamiento orteguiano", Reviste de Occidente, 2 época, Madrid, $\mathrm{n}^{2} 140$, noviembre, 1974- dice Rodriguez Huéscar que la posibilidad adquiere en Ortega "un rango metafísico de plena 'actualidad"' porque la realidad primaria y plenamente 'actual', gracias a su consistencia intrínsecamente tempórea, está hecha de 'posibilidades'"' (p. 197). 
la vida de cada cual predomine ora uno de esos costados, ora el otro.

La cuestión es que sí hay un aspecto de la realidad al que no llegan nuestras creencias:

"lo que solemos llamar realidad o 'mundo exterior' no es ya la realidad primaria y desnuda de toda interpretación humana, sino que es lo que creemos, con firme y consolidada creencia, ser la realidad" (V, 405).

Hay, pues, un segundo modo de darse lo real al yo, el modo del enigma o problema: "...el hombre se encuentra existiendo por partida doble, situado a la vez en la realidad enigmática y en el claro mundo de las ideas que se le han ocurrido" (V, 401).

Y desde el punto de vista de la realidad radical, es más radical la realidad como enigma que la realidad interpretada. Esta dualidad de modos de existir no es empírica, sino "metafísica", de realidad, y por ello la encontramos desplegada en otros muchos aspectos básicos de la descripción de la vida humana generados por la oposición fundante entre "mundo" y "trasmundo", entendiendo por trasmundo el cerco del horizonte de "lo que hay", un "más allá" y un "más acá" (respecto del yo) de lo que la experiencia humana no puede generar noticia positiva, pero de lo que tampoco puede prescindir. Así, pues, alteración y ensimismamiento; vida en sociedad, vida en soledad; vida como estar en creencias o vida como duda, menesterosidad y naufragio; vida como herencia, vida como creación, son aspectos de ese "doblez" -en el sentido de "dualidad", pero también en el de "mendacidad"- germinal de la circunstancia que es simultáneamente mundo y tras-mundo ${ }^{18}$.

\footnotetext{
18 Ese "trasmundo" no es propiamente "otro mundo", en el sentido platónico. Ortega no está deslizándose aquí hacia una metafísica dualista. El trasmundo es "algo" de este único "lo que hay" que se da al yo como "circunstancia", un fondo inabordable, un venero oculto, inaccesible a toda determinación de la razón tal y como es entendida por la filosofía, pero que se dio unido al mundo en el modo de pensar del mito. Esa seguridad inicial que genera visiones "verdaderas" en el hombre que vive en el mito se rompió un buen día y desde entonces el hombre sabe que habita en un mundo no-determinado, en un mundo que en su aparecer trasparenta un "error", una insuficiencia, un enigma "porque ese mundo se compone de meros e infinitos hechos inconexos entre si, consiste en acontecer esto y esto y
} 
Estas dualidades, verdaderas oposiciones que ninguna dialéctica logrará nunca mediar, no dependen del "modo" de actuar o de pensar el yo su instalación en el mundo, sino de la forma paradójica de serle la circunstancia al yo. De ahí que

"al hombre no le es dado ningún mundo ya determinado. Solo

le son dadas las penalidades y alegrías de su vida. Orientado por ellas, tiene que inventar el mundo. La mayor porción de él la ha heredado de sus mayores y actúa en su vida como sistema de creencias firmes. Pero cada cual tiene que habérselas por su cuenta con todo lo dudoso..." (V,394).

\section{Rigor de la distinción creencia / idea.}

Si bien las creencias y las ideas encierran aspectos epistemológicos (p.e. que las primeras son condición de posibilidad principios a tergo las denomina Ortega- de las segundas), psicológicos (las creencias tienen el carácter de ser "hábitos" o disposiciones) y sociológicos ${ }^{19}$ (las creencias, en cuanto vigencias, son colectivas), el único criterio suficiente de distinción es el de la diferencia de función que tienen en la estructura de la vida humana, pues ante una determinada situación la vivimos o "contando con" o "reparando en". Esta distinción de principio se complica -como ya sabemos- con otras. Veamos un cuadro de oposiciones:

CREENCIAS - contar con

IDEAS

-carácter de realidad

-continente de la vida

\section{-reparar en}

carácter revocable: fantasías contenidos del yo-conciencia

esto en infinito y arrollador torrente, en medio del cual se siente perdido" (XII,265). Por ello el hombre tiene que interpretar lo que hay para vivir, uno de cuyos modos es la filosofia.

19 A mi entender, no se incurre en contradicción con lo dicho en la nota 12. Allí no se critica a Morón Arroyo porque distinga aspectos en la oposición creencias/ideas, sino porque declara la incompatibilidad entre ellos. Es más, al proponer ahora un criterio funcional respecto de la vida humana -metafísico por tanto- sigo afirmando que lo epistemológico, sociológico o psicológico no constituyen criterios suficientes ni para establecer ni para comprender la diferencia entre creencias e ideas. 
-latentes para la conciencia

patentes a ella

-tienen vigencia

-colectivas

sin vigencia

individuales

- heredadas

creadas

Ahora bien, no todas las creencias exhiben todos los rasgos ni las ideas sus correspondientes. Si idealizamos la distinción, esto es, si tomamos creencia e idea como realidades puras, entonces sí que aparecerán nítidos estos rasgos. Pero en su realidad viviente creencias e ideas son variaciones ocasionales y escalares ${ }^{20}$ de un mismo género, del género "interpretación". Esto supone que puede haber "entidades" intermedias entre las creencias puras y las ideas puras.

Marías establece la siguiente jerarquía de interpretaciones:

creencias tradicionales
creencias de autoridad
opiniones recibidas
experiencias de la vida
[supuestos tácitos]
ideas-conocimiento
ideas-ocurrencia
ideas-auténticas

20 "Creencia" es una categoría que pertenece a la "teoría general de la vida humana". Como tal categoría, no es una determinación del ser o del conocimiento, sino un mero leere Stelle, un concepto ocasional que hay que llenar de contenido para que signifique algo y que por lo mismo admite variaciones en su forma de referirse a la realidad que pretende determinar.

Puesto que este modo de entender las categorías implica un cambio radical respecto de la tradición -tanto en Aristóteles, como en Kant- no cabe aquí entrar en detalles. El mejor estudio y más clarificador es el de A. Rodríguez Huéscar, La innovación metafísice de Ortega, Madrid, M. de Educación y Ciencia, 1982. Véase la segunda parte, "Superación del idealismo: Las categorias de la vida" (pp. 103 y ss.) que arranca con un análisis del significado de lo categorial en Ortega.

${ }_{21}$ Introducción a la filosofía, Madrid, Alianza, 24 ed., 1981, p. 104. La enumeración de Marías tiene la virtud de presentar en un continuo las dos categorías absolutas de "creencia" e "idea".

Respecto de las "experiencias de la vida", un complejo concepto que Ortega no llegó a sistematizar del todo, véase VI,37; VII,495; IX,16. En este último lugar se dice: "Las expectativas no se originan en razonamientos nuestros que en cualquier 
Algunas de las ideas de la lista pueden ser interpretadas como cuasi-creencias, entendiendo por tales, determinadas ideas que están camino de convertirse en creencias pero que aún no han terminado su proceso de conversión. La nocividad del tabaco podría ser un caso de cuasi-creencia, a medio camino entre la "creencia de autoridad" y la "idea recibida". Con este ejemplo sugiero que determinados contenidos pueden coexistir en estado de creencias (para algunas vidas) y en estado de ideas (para otras). Recuérdese que es dentro de la propia vida -en vista de su proyecto- como se articula el sistema de creencias: "sólo en función del drama vital -señala Marías- a que sirve es sistemático el repertorio de las creencias" 22 . Las ideas de opinión pública -ideas reinantes en amplios sectores de la sociedad- son discutibles y patentes, esto es, son ocurrencias, pero tienen vigencia, característica de las creencias.

Si bien toda creencia tiene necesariamente vigencia, la creencia es un caso particular de vigencia. Puede haber vigencias que no sean creencias:

1. Hay vigencias que no son interpretaciones, sino comportamientos, estimaciones, instituciones, personas, profesiones, etc.

2. Hay interpretaciones vigentes que no son creencias sino ideas: "hay ideas y opiniones que las pensamos porque las hemos oído y porque se dicen" (VII,198).

momento podemos improvisar, sino que, como he dicho, se forman ellas mismas espontáneamente en nosotros por una paulatina decantación de experiencias y, por tanto, lentamente".

Marías no da los supuestos tácitos -de ahí que vayan entre corchetes. Los he añadido para no confundirlos con las creencias en sentido estricto. Estas son supuestos no solo actual, sino potencialmente inexpresos, a diferencia de aquellos supuestos tácitos que se rinden a una investigación metodológicamente bien planificada. Villoro, en el artículo citado supra (ver nota 4), que acusa a Ortega de confusión epistemológica, por creer que creencia/idea equivale a contenido implícito / explícito de la conciencia, sigue dependiendo de un modelo idealista de razón, capaz de fundar todos sus contenidos sobre sí misma. Para Ortega esto no es posible: las creencias no son accesibles al análisis racional directo o sincrónico.

La estructura social, p. 131. 


\section{Función de las ideas.}

No se ha dicho que la totalidad del argumento de la vida esté amparado, asegurado por el sistema de creencias. $Y$ tampoco que las creencias que son para el viviente la realidad misma, no sean contradictorias entre sí, o haya, en un momento histórico dado, más de un sistema de creencias, 0 , simplemente, que no dejen de funcionar como tales, abandonando al yo a la ingrata tarea de vivir en el hueco o vacío funcional de aquello que antes la creencia llenaba con su vigencia.

Hay, al menos, dos dimensiones de la vida humana que hacen del sistema de creencias algo insuficiente, esto es, expuesto a lo problemático. En primer lugar, la temporalidad de la vida humana coimplica en su actualidad dos latencias, la del pasado, dimensión a que pertenecen las creencias, y la del futuro; si la primera contiene y cierra a la vida en su actualidad, la segunda la abre a lo desconocido e inseguro, a lo imprevisible y azaroso. La temporalidad de la vida revela la historicidad radical de las creencias. En segundo lugar, la acomodación de las creencias -que son siempre colectivas- al propio proyecto, a la vocación individualísima que el yo tiene que realizar en su vida, las somete a una especie de tensión que puede volverlas insuficientes para el proyecto en cuestión. (Aunque las creencias determinan el ámbito de lo posible y de lo imposible -como se ha dicho- siendo por tanto el sostén del proyecto, éste puede romper el cerco de ese posible-contingente definido por las creencias y aspirar literalmente a lo imposible. Lo imposible -que "posee a veces la gracia de ocurrir", como dice Conrad- es una dimensión permanente de lo humano, inscrita en su existir por la dimensión de libertad y creatividad que lo constituyen. (Creencias y vocación, en tanto que determinaciones de los dos ingredientes inseparables pero opuestos de toda realidad humana, circunstancia y yo, respectivamente, se necesitan mutuamente para constituirse y se condicionan, pero no se subsumen uno en el otro, antes bien, están en tensión permanente.)

La actuación del yo en su circunstancia se apoya en un suelo sólo parcialmente firme. Su vida es para cada cual inseguridad en 
todo aquello que no queda amparado por el sistema de soluciones de las creencias. Por sus huecos y desgarrones se deja ver la desnudez problemática en que consiste últimamente el vivir, el problema que cada vida es para sí misma, en el siguiente sentido: "Algo me es problema, no porque ignore su ser, no porque no haya cumplido mis supuestos deberes de intelectual frente a ello, sino cuando busco en mí y no sé cual es mi auténtica actitud con respecto a ello, cuando entre mis pensamientos sobre ello no sé cual es rigorosamente el mío, el que de verdad creo, el que coincide conmigo (...) El problema sustancial, originario y en este sentido único, el encajar yo en mí mismo, coincidir conmigo, encontrarme a mí mismo" (V,86).

No saber a qué atenerse es dudar. La duda es una situación vital del mismo género que creer, solo que de signo opuesto: es creer que no se cree. Si reducimos la duda a una operación metódica de la razón, perderemos de vista que dudar es un suceso sobrevenido, algo que acontece -es decir, que se le impone- a un yo. Más tarde, la duda será pensada, aunque no necesariamente, y aparecerá en el ámbito de la conciencia como especulación y juego -por más que sea "muy en serio"- de ideas que ocultan un real conflicto entre creencias. Pero existía ya vitalmente como fractura de (o conflicto entre) creencias antes de que el pensamiento acusara recibo.

La duda intelectual es un producto del ensimismamiento, aquello que hacemos cuando en la alteración de nuestro vivir llegamos a no saber bien qué hacer; y eso que hacemos es pensar. "Los huecos de nuestras creencias son pues el lugar vital donde insertan su intervención nuestras ideas" $(V, 394)$. En la duda uno no se puede sostener por mucho tiempo. Porque la duda es lo infirme: en la duda se está en "un mar de dudas". Y salimos de la duda pensando, construyendo ideas:

"Todo lo que en este mundo real encontramos de dudoso o insuficiente nos obliga a hacernos idea sobre ello. Esas ideas forman los 'mundos interiores' en los cuales vivimos a sabiendas de que son invención" $(V, 405)$. 
Estos "mundos interiores" no son más que interpretaciones verosímiles, conjuntos de hipótesis, narraciones que nuestra intimidad se organiza para saber momentáneamente a qué atenerse. El rasgo común a todos los mundos interiores ${ }^{23}$ : "que son obra de nuestra fantasía" $(\mathrm{V}, 406)$.

Ortega les denomina "mundos" porque tienen orden y congruencia, tanto dentro de ellos mismos, como entre sí, e "interiores" porque son fruto de la intimidad individual, del yo que los imagina. Otra cosa es que luego esos mundos se objetiven adquiriendo una apariencia de independencia de las mentes que los concibieron, cosa que ocurre cuando un mundo interior alcanza algún modo de vigencia y comienzan a tener una existencia institucionalizada. Pero entonces, lo que ocurre es que esas fantasías han demostrado alguna capacidad efectiva de orientación para la vida, segregando soluciones prácticas. El mundo interior de la ciencia físico-matemática ha tenido un inmenso poder de institucionalización por las aportaciones técnicas y de manipulación de la naturaleza en que se ha materializado. No hay que olvidar que los mundos interiores, por más que sean hijos de la fantasía, no flotan en una especie de éter ignoto, sino que se hayan vinculados estructuralmente a la realidad "exterior", a cuyos problemas e insuficiencias son respuesta, así como al sistema de creencias que actúa como conjunto de principios inexpresos a la espalda de las ideas efectivamente pensadas. De ahi que los mundos interiores no tengan una existencia arbitraria, sino que responden a una economía de la vida humana estando engarzados o "encajados por nosotros dentro del mundo real o exterior, formando una gigantesca articulación" $(V, 406)$. Lo que proporciona esta articulación y determina la estructura de los mundos interio-

23

Lo que denomina Ortega mundos interiores es lo que llamamos habitualmente "teoría" y sus producciones. Pero no sólo son teorías las que elabora el conocimiento, en el sentido moderno del término, esto es, las ciencias que buscan las leyes de la naturaleza o de la sociedad; la religión, la poesía, la sabiduría práctica o de costumbres -lo que los franceses llaman sagesse- son otros tantos mundos interiores. 
res entre sí es un sistema de creencias. El porqué en una época es la ciencia y en otro la religión el mundo interior dominante - aquel al que se orientan los hombres espontáneamente en su ensimismamiento (porque "esperan" que contenga las respuestas efectivas a sus problemas)- depende de la creencia dominante en ese momento, esto es, del principio de orientación que domina el paisaje histórico; en este caso, la creencia en Dios o la creencia en la razón humana.

Las creencias, pues, estructuran las épocas históricas. El hombre no pertenece a la naturaleza, sino a un mundo configurado históricamente por sus sistemas de creencias, usos, vigencias, experiencias de vida, etc. Éste es el contexto en que habría que interpretar la muy radical y peliaguda tesis orteguiana que niega que el hombre tenga naturaleza porque es "historia": "que el hombre no es una cosa, que es falso hablar de la naturaleza humana, que el hombre no tiene naturaleza" (VI,24). Y un poco más adelante, añade: "El hombre no es cosa ninguna, sino un drama, su vida, un puro y universal acontecimiento..." (VI,32). Y para aclarar en qué sentido sí se puede decir que el hombre tiene o posee una "naturaleza": "...lo único que el hombre tiene de ser, de 'naturaleza', es lo que ha sido. El pasado es el momento de identidad del hombre, lo que tiene de cosa, lo inexorable y fatal" $(\mathrm{VI}, 39)$. Me he limitado a exponer la tesis orteguiana en la versión de Historia como sistema porque es, creo, su formulación más aguda y porque es la que mejor revela su conexión con la doctrina de la creencia, único aspecto que interesa aquí. Ortega no niega que el hombre tenga un cuerpo, con sus sistemas nervioso, glandular, digestivo, circulatorio, etc; y hasta un "alma" o "psique" -sea cual sea su soporte bio-químico- que cuentan a la hora de vivir. Lo que señala es que cuerpo y alma no son "datos" o "hechos" -ni siquiera en bruto- para el vivir humano, que es siempre un actuar históricamente localizado: la realidad del hombre es acontecimiento, no cosa, no un algo estático que posee atributos, modos, accidentes, propiedades. Claro que el hombre tiene "propiedades", pero éstas se dan determinadas históricamente: por ejemplo, no hay una 
necesidad natural-sexual del cuerpo, sino una "necesidad" contextualizada en una tradición de usos, creencias, hábitos y hasta "fantasías" que son los "datos relevantes" con los que el viviente se enfrenta a la hora de decidir qué hacer ante su deseo o necesidad sexual. Por ello he añadido la tercera cita; porque señala que las cosas del hombre son históricas: son su pasado, tanto individual como colectivo o social. En este sentido, el cuerpo es para el hombre algo que está en su pasado: algo que da por descontado cuando actúa. Si no puede contar con su cuerpo es que se halla en una situación de la que el cuerpo mismo es ingrediente problemático. Para entonces el cuerpo está en el futuro: habrá que hacer algo con él. Era "cosa" cuando vivía a la espalda del yo, sin hacerse sentir; pero ahora no es un "algo" dócil a su mandato, sino un enigma; ha dejado de ser "una natu-raleza" para ser acontecimiento, el de una enfermedad. Lo que constituye la dimensión de realidad de la vida humana es el sistema de creencias y éste es el pasado del hombre. Si se asocia la creencia -que psicológicamente tiene bastante de "hábito"- a lo que Aristóteles llamó segunda naturaleza del hombre, el sistema de hábitos y costumbres adquiridos por éste mediante su obrar en el mundo, la tesis de Ortega no resulta tan distante del más grande filósofo de la naturaleza humana. Y tampoco de Hume, el filósofo moderno que más hincapié ha hecho en la naturaleza humana, hasta el punto de fundar el conocimiento y la moralidad en ciertos mecanismos ocultos de esa human nature, algunos de los cuales serían de carácter creencial. Al igual que Ortega, Hume mantiene que las creencias son "el principio regulador de nuestras acciones" ${ }^{\prime 24}$. Esta notable coincidencia no debe hacernos ignorar una diferencia de

24 Investigaciones sobre el conocimiento humano, Madrid, Alianza, p. 73. Un poco antes, escribe: "Se sigue, por tanto, que la diferencia entre ficción y creencia reside en algún sentimiento o sensación que se añade a la última, no a la primera, y que no depende de la voluntad ni puede manipularse a placer" (p. 71). También las creencias son en Hume lo que pone realidad, frente a las meras ideas o ficciones; de ahí que subraye la autonomia de la creencia respecto de la voluntad, como hace Ortega. 
raíz: para el español las creencias son una realidad "producida" históricamente por la dinámica de la vida colectiva, mientras que para el escocés es una disposición natural -exactamente un "modo de representación" (conception)- de la mente humana, un sentimiento (feeling) que acompaña a determinadas ideas y que no cabe explicar: "no podemos ir más lejos de afirmar que la creencia es algo sentido por la mente que distingue las ideas del juicio de las ficciones de la imaginación" (op. cit., p. 73). Ortega no pretende "explicar" el origen de las creencias, pero sí ha conseguido arrojar luz sobre su papel decisivo en la articulación histórica de las vidas humanas, tanto en lo individual como en lo colectivo. El hombre no tiene una naturaleza "cerrada", sino que vive alimentado por la tradición, que es, en lo fundamental, un sistema de creencias: "El sistema de la tradición viene a ser, en el hombre, un sucedáneo del sistema de los instintos que como animal perdió. En la medida en que estamos sumergidos dentro de una tradición vivimos sus formas 'instintivamente'. Esta es la vida del puro 'creyente', de la radical 'fe'" $(\mathrm{VI}, 404)^{25}$.

${ }^{25}$ Los problemas relativos a la estructura histórica de la vida humana a partir de la distinción entre creencias e ideas están lejos de haber sido agotados, siquiera planteados todos ellos, en esta aproximación. Por citar algunos: no se ha entrado en la peculiar relación entre creencia y filosofía. Tampoco se ha podido abordar la cuestión de la formación y desaparición de las creencias y ha quedado abierta la cuestión del fondo metafísico de la vida humana: si es creencial o si hay algo detrás. De ahí que este artículo concluya con la exigencia de continuarse en otro donde se traten las cuestiones aquí aplazadas. 